\title{
Edukasi Penggunaan Instalasi Listrik Yang Baik Untuk Menghindari Bahaya Kebakaran Akibat Listrik Di Kelurahan Gondrong Kecamatan Cipondoh Kota Tangerang
}

\author{
Kartika Tresya Mauriraya ${ }^{1}$; Rio Afrianda ${ }^{2}$; Nurmiati Pasra ${ }^{3}$; Novi Gusti Pahiyanti ${ }^{4}$; \\ Andi Makkulau; ${ }^{5}$ Alex Fernandes ${ }^{6}$; Sigit Sukmajati ${ }^{7}$ \\ 1, 2, 3, 4, 5, 6,7 Institut Teknologi PLN \\ ${ }^{1}$ kartika@itpln.ac.id
}

\begin{abstract}
This community partnership program aims to help the public to know the security of residential installations and fire prevention efforts due to an electrical surge. As well as providing motivation to be able to continue to encourage and apply to the community in the partner area to always prevent fires due to electrical short circuit and use electrical equipment according to standards. With the partnership program activities of the community in the Gondrong neighborhood, Cipondoh Subdistrict will be able to provide education on integrated electrical installations to avoid fire hazards due to electricity.
\end{abstract}

Keywords: Installation of houses, electric short circuit, fire prevention

\begin{abstract}
ABSTRAK
Program kemitraan masyarakat ini bertujuan untuk membantu masyarakat mengetahui pengamanan instalasi rumah dan upaya pencegahan kebakaran akibat adanya konsleting listrik. serta memberikan motivasi untuk dapat terus mendorong dan menerapkan ke masyarakat di wilayah mitra untuk selalu mencegah kebakaran akibat konsleting listrik dan menggunakan peralatan listrik sesuai standar. Dengan adanya kegiatan program kemitraan masyarakat di lingkungan Kelurahan Gondrong, Kecamatan Cipondoh akan mampu memberikan edukasi penggunaan instalasi listrik yang baik untuk menghidari bahaya kebakaran akibat listrik.
\end{abstract}

Kata kunci: Instalasi rumah tinggal, Konsleting listrik, pencegahan kebakaran 


\section{PENDAHULUAN}

Data statistik DKI penyebab utama kebakaran adalah listrik (48\%) dan obyek yang banyak terbakar adalah perumahan ${ }^{[1]}$. PT. PLN selaku pemasok energi listrik, sampai saat ini hanya memasang KWH meter sebagai alat pengukur pemakaian energi dan $\mathrm{MCB}$, sebagai pembatas daya tersambung. Oleh sebab itu pelanggan harus dapat mempersiapkan sarana pelindung instalasi listrik yang dapat mengantisipasi kemungkinan timbulnya bahaya kebakaran karena listrik. Perlengkapan listrik tidak boleh menimbulkan bahaya kebakaran terhadap bahan yang berada didekatnya ${ }^{[2]}$. Pada saat pekerjaan instalasi listrik sudah selesai dikerjakan oleh instalatir listrik, sebelum hasil pekerjaan diserah terimakan dan sebelum PLN menyambungkan tegangan listrik, terhadap hasil pekerjaan tersebut harus dilakukan pengecekan dan pengujian oleh lembaga pemeriksa, penguji dan sertifikasi (Konsuil). Jika hasil pemeriksaan dan pengujian memenuhi syarat dan sesuai standar, maka dikeluarkan Sertifikat Layak Operasi (SLO), setelah itu diijinkan untuk dilakukan penyambungan tegangan listrik oleh petugas PLN. Jika hasil pemeriksaan dan pengujian memenuhi syarat dan sesuai standar, maka dikeluarkan Sertifikat Layak Operasi (SLO), setelah itu diijinkan untuk dilakukan penyambungan tegangan listrik oleh petugas PLN.

Namun kondisi sekarang yang terjadi dimasyarakat yang ada yaitu lalainya masyarakat dalam melakukan berbagai hal yang bisa menimbulkan terjadinya kebakaran, seperti banyaknya masyarakat yang tidak menggunakan material bahan listrik yang sudah mendapatkan sertifikasi keamanan, hal ini yang sering menyebab konsleting listrik dan dapat menimbulkan terjadinya kebakaran, dan apabila terjadi kebakaran di pemukiman padat biasanya sering terjadi kebakaran besar yang di sebabkan oleh beban api yang tinggi, dan juga padatnya bangunan yang saling berdempetan di wilayah pemukiman, yang pada umumnya material bangunannya adalah material bangunan yang mudah sekali terbakar. Hal ini yang sering merambatnya kebakaran ke beberapa titik bangunan yang berada di wilayah pemukiman padat, di tambah lagi sulitnya pemadaman yang dilakukan karena beberapa faktor yang menghambat pemadaman pada saat terjadinya kebakaran. Terhambatnya pemadam kebakaran saat memadamkan kebakaran karena akses jalan yang sempit berupa jalan atau gang kecil yang sulit untuk mendekat ke lokasi kebakaran untuk memadamkan api adalah faktor yang menghambat pemadaman.

Untuk membatasi perilaku yang kurang baik dalam penggunaan instalasi listrik, maka harus dilakukan edukasi penggunaan instalasi listrik yang baik untuk menghindari bahaya kebakaran akibat listrik. Dengan langkah ini diharapkan listrik sebagai pemicu awal kebakaran dapat dicegah. Permasalahan yang sedang dihadapi oleh mitra adalah kurangnya edukasi tentang pengamanan instalasi listrik terpadu kepada masyarakat. Dengan adanya kegitan pelatihan ini, akan memberikan informasi berupa pengetahuan dan pemahaman mengenai pentingnya pengamanan instalasi listrik terpadu melalui kegiatan pelatihan agar masyarakat mengetahui dan memahami penyebab terjadinya kebakaran serta cara mencegah bahaya kebakaran. Sehingga, tingkat kewaspadaan masyarakat lebih meningkat.

\subsection{Sistem Instalasi Listrik Rumah}

Energi listrik sangat bermanfaat dan sangat dibutuhkan dalam kehidupan manusia, karena listrik memiliki fungsi dan manfaat yang sangat vital dan strategi dalam kehidupan masyarakat dan merupakan kebutuhan pokok sehari-hari dalam mendorong pembangunan nasional di segala bidang. Masih banyak masyarakat yang belum mengetahui tentang syarat-syarat sistem pemasangan instalasi listrik dan daya tahan penggunaan peralatan/perlengkapannya, serta instalasi listrik yang sudah terpasang lama pada rumah dan gedung, yang seharusnya memenuhi ketentuan dan peraturan yang berlaku. Dimana instalasi listrik yang sudah lama terpasang seharusnya dilakukan pegecekan ulang 
kelayakan instalasinya. Jika kelayakannya sudah tidak memenuhi persyaratan pakai harus diganti, pengecekan kelayakan ini harus dilakukan oleh instansi yang ditunjuk minimal 10 tahun sekali, sehingga kemungkinan terjadinya kecelakaan dan kebakaran akibat instalasi listrik dapat dihindari.

\subsection{Menghindari Bahaya Gangguan Listrik}

Terdapat faktor lain penyebab kebakaran, seperti masyarakat saat memanfaatkan arus listrik membagi-baginya dengan menggunakan stop kontak cabang lebih dari 4 sumber, hal ini akan berdampak fatal yaitu keluarnya bunga api penyebab awal kebakaran. Apabila jumlah stop kontak yang terpasang melebihi batas kemampuan arus listrik maka akan menyebabkan kabel pada stop kontak akan menjadi panas. Perlu diketahui bahwa memasukkan stop kontak ke kotak kontak adalah merupakan sambungan arus listrik sementara, jika antara stop kontak dan kotak kontak tersebut tidak terpasang dengan benar (kendor) maka dapat mengakibatkan timbulnya percikan bunga api atau panas yang tinggi. Jika panas itu terjadi dalam waktu yang relatif lama, maka hal ini akan menyebabkan melelehnya box stop kontak .

Hubung singkat (korsleting listrik) terjadi karena adanya hubungan kawat positip dan kawat negatip yang beraliran listrik, atau dapat juga terjadi akibat kebocoran isolasi kabel. Hal ini karena sistem sambungan yang kurang tepat, isolasi kabel yang rusak disebabkan kecerobohan saat pemasangan instalasi, akibat gigitan binatang, peralatan sudah tua dan mutu peralatan serta kabel jelek, penampang kabel terlalu kecil yang tidak sesuai dengan beban listrik yang mengalirinya.

\section{METODE}

\subsection{Diagram Alir Kegiatan}

Metode pelaksanaan yang digunakan dalam pelaksanaan PKM adalah sebagai berikut. (1) pembagian tim PKM, (2) Merancang Program Kemitraan Masyarakat, (3) Menyusun program dan proposal PKM, (4) Pengadaan dan pembuatan modul penunjang PKM, (5) Pendaftaran dan Penentuan Peserta Pelatihan PKM, (6) Melakukan Pelatihan dan praktek Pengamanan Instalasi Listrik Terpadu. 


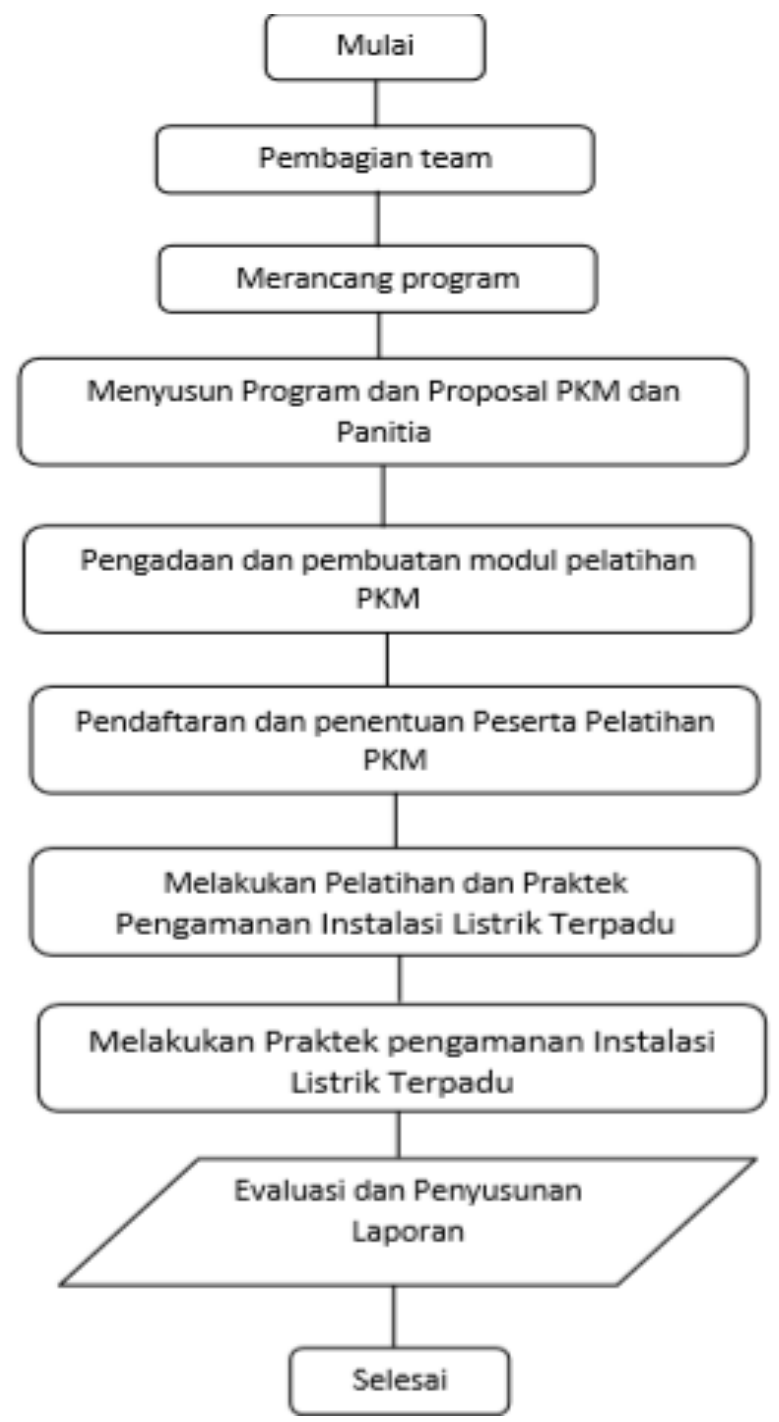

Gambar 1. Digram Alir Metode Pelaksanaan PKM

\subsection{Sifat dan Bentuk Kegiatan}

Edukasi Instalasi Listrik Bagi Masyarakat di keluraham Gondrong kecamatan Cipondoh kota Tangerang akan dilakukan dalam Satu Sesi diikuti oleh 30-40. Setiap peserta akan diberikan materi berupa pengetahuan disertai dengan simulasi TIM.

Langkah 1: Masyarakat diberikan informasi tentang teori dasar-dasar Instalasi listrik.

Langkah 2: Setelah mendapatkan teori tentang instalasi listrik, masyarakat melihat simulasi yang diberikan oleh TIM

Langkah 3: Setiap peserta dipersilahkan untuk bertanya, jika terdapat hal yang belum dimengerti

Langkah 4: Melakukan pengamatan dan observasi untuk mengetahui dampak/ hasil yang tampak saat pelaksanaan, dan dilanjutkan dengan laporan hasil pengamatan

Langkah 5: Mengevaluasi hasil kegiatan pada masyarakat yang dilaksanakan

Langkah 6: Membuat laporan pertanggung jawaban pelaksanaan kegiatan pengabdian pada masyarakat. 


\section{HASIL DAN PEMBAHASAN}

Pengabdian masyarakat ini didahului dengan proses survei pada awal bulan September 2017. Dari hasil survei tersebut dan setelah mendapatkan persetujuan kami melakukan pengabdian kepada masyarakat dengan tema "Edukasi Penggunaan Instalasi Listrik yang Baik untuk Menghindari Bahaya Kebakaran Akibat Listrik di Kelurahan Gondrong Kecamatan Cipondoh Kota Tangerang" dan diikuti oleh segenap civitas dan masyarakat sekitar 40 orang yang dibuka oleh sambutan dari bapak RW. 06/02 di Kelurahan Gondrong Kecamatan Cipondoh kota Tangerang.

Tim PKM IT-PLN menjelaskan mengenai beberapa penyebab kebakaran akibat konsleting listrik dan kurangnya kesadaran masyarakat terhadap penggunaan listrik yang aman. Untuk memberikan pengenalan dan sosialisasi tentang perilaku yang kurang baik dalam penggunaan instalasi listik, maka tim memberikan pemahaman model sistem instalasi listrik dengan pengaman terpadu, agar dapat mencegah tindakan penyelewengan penggunaan instalasi listrik di luar peruntukannya. Dengan langkah ini diharapkan listrik sebagai pemicu awal kebakaran dapat dicegah. Dari kegiatan tersebut antusias dari peserta sangat baik, hal ini dapat terlihat dimana mereka kebanyakan telah mempersiapkan diri untuk bertanya dalam hal topik tersebut. Dari kegiatan tersebut antusias dari peserta sangat baik, hal ini dapat terlihat dimana mereka kebanyakan telah mempersiapkan diri untuk bertanya dalam hal topik tersebut.
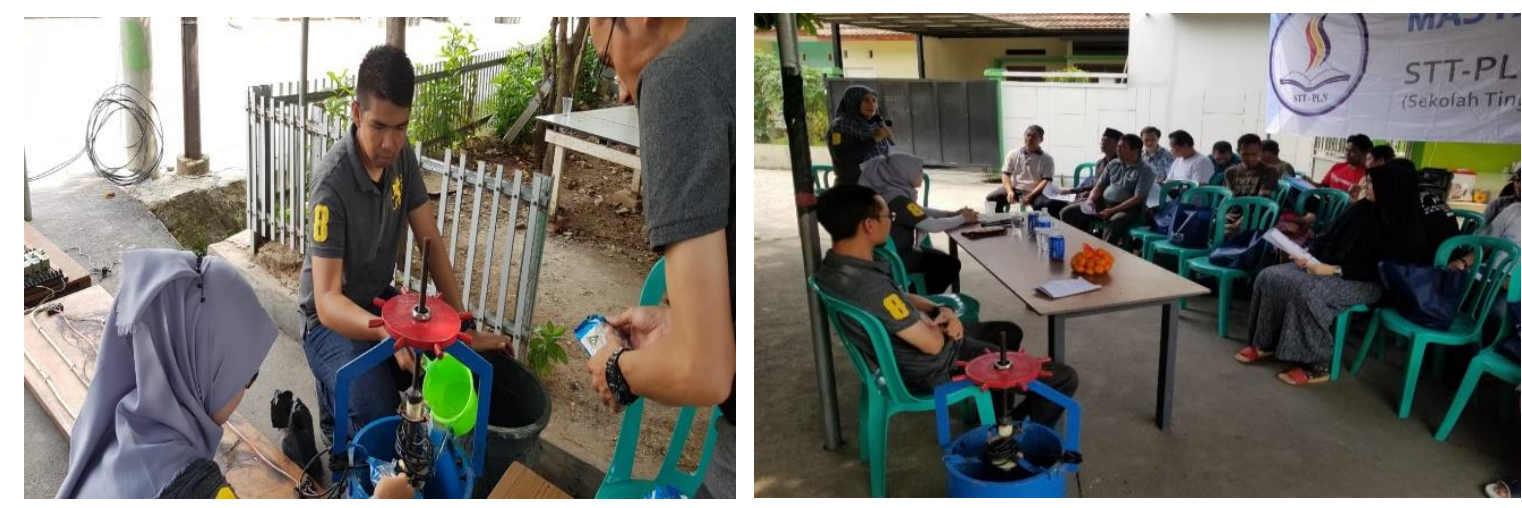

Gambar 2. Foto Persiapan dan Pembukaan Kegiatan PkM
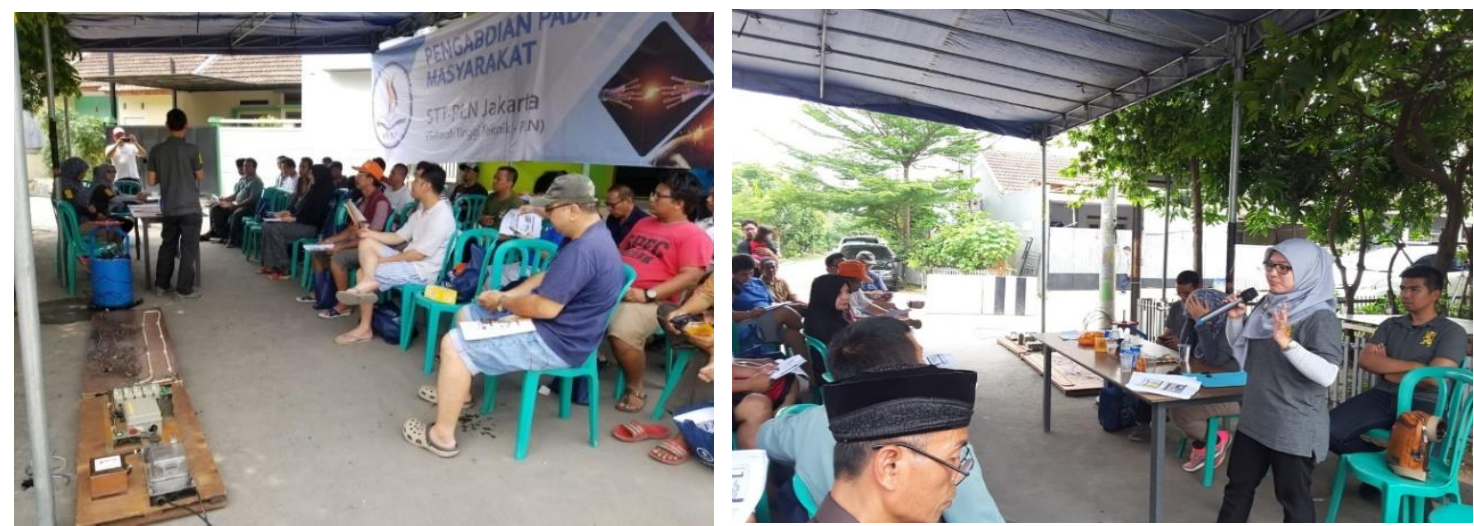

Gambar 3. Penyampaian Materi Kegiatan PKM 

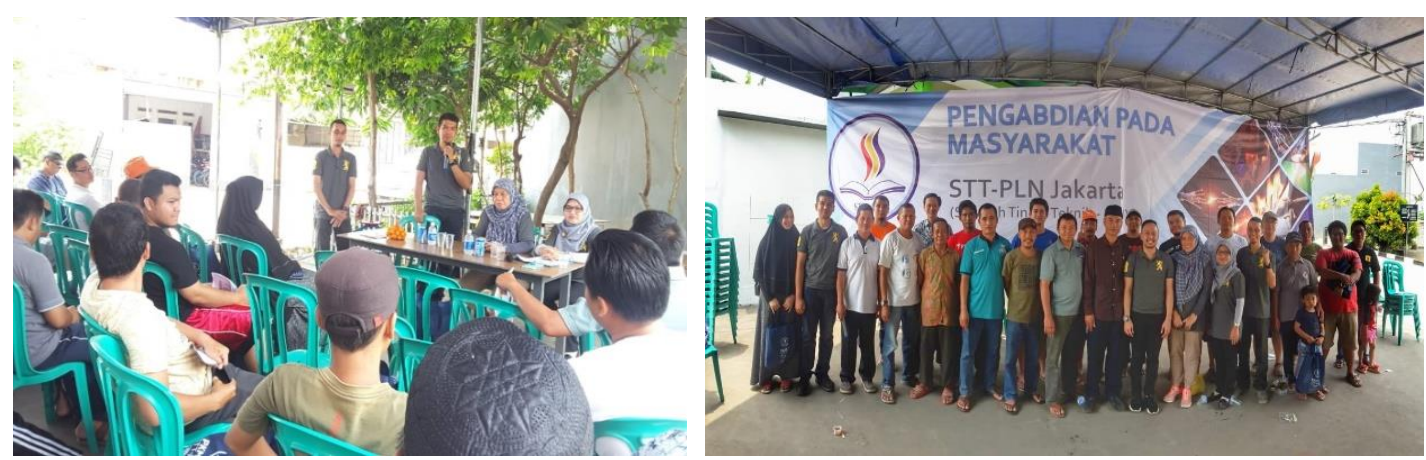

Gambar 4. Foto Bersama Peserta Kegiatan PkM

Kegiatan edukasi penggunaan instalasi listrik yang baik untuk menghindari bahaya kebakaran akibat listrik di Kelurahan Gondrong Kecamatan Cipondoh Kota Tangerang seperti ini pada tahap berikutnya akan terus dilaksanakan baik itu di dalam lingkungan IT-PLN itu sendiri maupun di luar lingkungan IT-PLN, karena dari kegiatan seperti ini dapat memberikan manfaat yang besar terutama bagi masyarakat pada umumnya. Kegiatan seperti ini harus terus dilakukan terlebih karena saat ini sudah kurangnya kesadaran masyarakat dalam hal instalasi listrik yang sesuai standar.

Rencana tahapan berikutnya, edukasi penggunaan Instalasi Listrik yang Baik untuk menghindari Bahaya Kebakaran Listrik Ini akan dilakukan di Kelurahan Cipulir Kecamatan Kebayoran Lama Kota Jakarta Selatan.

\section{KESIMPULAN}

Pelaksanaan kegiatan ini mendapatkan dukungan dari pihak kelurahan Duri Kosambi karena melalui kegiatan ini segenap civitas dan warga masyarakat Kecamatan Gondrong dapat memahami mengenai Edukasi Penggunaan Instalasi Listrik yang Baik Untuk Menghindari Bahaya Kebakaran Akibat Listrik Di Kelurahan Gondrong Kecamatan Cipondoh Kota Tangerang. Pelaksanaan kegiatan ini mendapatkan perhatian dari peserta khususnya warga RT.006/002 di Kelurahan Gondrong Kecamatan Cipondoh Kota Tangerang dimana mereka menyambut baik pelatihan ini karena dapat memberikan bekal yang bermanfaat bagi mereka nantinya. Kegiatan memberikan motivasi untuk dapat terus mendorong dan menerapkan edukasi serupa kepada mitra agar selalu meningkatkan kewaspadaan kebakaran akibat peralatan listrik yang tidak sesuai standar.

\section{SARAN}

Diharapkan kegiatan semacam ini diharapkan dilakukan kembali karena ini sangat bermanfaat untuk kita pada umumnya karena dapat memberikan pemahaman dan bekal ilmu kepada masyarakat agar dapat mencegah kebakaran akibat konsleting listrik karena penggunaan instalasi listrik yang tidak sesuai.

\section{UCAPAN TERIMA KASIH}

Salah satu Tri Darma Perguruan Tinggi adalah mengadakan Program Kemitraan Masyarakat (PkM) sebagai bentuk apresiasi terhadap masyarakat sekitar perguruan tinggi. Puji syukur Alhamdulillah atas kehadirat Allah SWT, yang telah melimpahkan Rahmat dan Hidayah-Nya sehingga kami dapat melaksanakan kegiatan Program Kemitraan Masyarakat (PkM) dengan tema "Edukasi Penggunaan Instalasi Listrik yang Baik untuk Menghindari Bahaya Kebakaran Akibat Listrik di Kelurahan Gondrong Kecamatan Cipondoh Kota Tangerang”. Terselesainya 
Pengabdian Pada Masyarakat ini tentu berkat kekompakan tim PKM serta dukungan orang-orang terdekat. secara khusus kami mengucapkan terimakasih kepada:

1. Supriadi Legino ST., MT Ketua Sekolah Tinggi Teknik PLN yang telah memberikan kesempatan serta dukungan kepada TIM P2M.

2. Indrianto, S. Kom., MT, selaku ketua Lembaga Penelitian dan pengabdian Pada Masyarakat (LP3M) Sekolah Tinggi Teknik PLN yang telah memberikan wadah pengabdian pada masyarakat.

3. Erlina, ST., MT, selaku Kepala Prodi Teknik Elektro Sekolah Tinggi Teknik PLN yang telah memberikan ijin untuk melaksanakan PKM.

4. Nurmiati Pasra, ST., MT, selaku Ketua Prodi D-III Teknik Elektro Sekolah Tinggi Teknik PLN yang telah membentuk TIM serta memberikan arahan pada TIM untuk melaksanakan PKM.

Tak ada gading yang tak retak, kekurangan dan kesalahan tentu masih ada, untuk itulah tim PKM membutuhkan kritik dan saran yang membangun dalam menyempurnakan pelaksanaan Pengabdian Pada Masyarakat mendatang.

\section{DAFTAR PUSTAKA}

[1] Electrical Fire Causes, tersedia di http://www.waltersforensic. com/fire/vol5- No 2.

[2] Electromagnetic Fields in Mechatronics, Electrical and Electronic Engineering Arras, France, September 10-12, 2009 